\title{
Experimental determination of highly dynamic forces during wood trunk comminution with a drum chipper
}

\author{
Philip Pichler, ${ }^{1}$ Martin Leitner, ${ }^{1}$ Florian Grün, ${ }^{1}$ Christoph Guster ${ }^{2}$ \\ ${ }^{1}$ Mechanical Engineering, Montanuniversität Leoben; ${ }^{2}$ KOMPTECH GmbH, Austria
}

\begin{abstract}
Using large wood chips for heating systems in industrial applications is becoming popular. As a result, the requirements of the machinery that produces these large wood chips have increased, especially on the chipping tools and on the surrounding supportive components. This paper evaluates the acting main forces on a chipping drum that produces large wood chips via field and laboratory-based experimental measurements. In this study, a variety of strain gauges are applied to selected areas of the rotating chipping drum to measure localised strain conditions during wood-stem cutting. Four different wood species were investigated for comparison. Furthermore, the influence of sharp and dull knives is analysed. With the aid of experimental measurements and analysis on a laboratory scale, linear models are developed to determine the chipping force, which is cutting depth-dependent, for a variety of wood species. Testing parameters for such models are proposed via load spectra. The variability of the acting force value is evident. The maximum load on the drum affects at $10 \%$ of the time of a single cut. The largest applied forces are between 1.6 and 1.8 higher than the calculated average force. The commuting hornbeam sample exhibits the highest resistance against chipping compared to the three-other species. Additionally, a change in the load is easily recognised in the field test when utilising dull chipping blades. A reconstruction of the alternate load direction is based on laboratory testing.
\end{abstract}

Correspondence: Philip Pichler, Mechanical Engineering, Montanuniversität Leoben, Austria.

E-mail: philip.pichler@unileoben.ac.at

Key words: Wood chipping; forces; drum; experimental; field; laboratory.

Acknowledgments: this work was conducted by the Chair of Mechanical Engineering at the Montanuniversität Leoben, in cooperation with Komptech GmbH. Special thanks are given to the Austrian Research Promotion Agency (FFG), who founded the research project by funds of the Federal Ministry for Transport, Innovation and Technology (BMVIT) and the Federal Ministry of Economics and Labour (BMWA), and to all the industry partners for the supply of material and the fabrication work done.

Received for publication: 12 September 2017.

Accepted for publication: 12 November 2017.

(C) Copyright P. Pichler et al., 2018

Licensee PAGEPress, Italy

Journal of Agricultural Engineering 2018; XLIX:786

doi:10.4081/jae.2018.786

This article is distributed under the terms of the Creative Commons Attribution Noncommercial License (by-nc 4.0) which permits any noncommercial use, distribution, and reproduction in any medium, provided the original author(s) and source are credited.

\section{Introduction}

Since the discovery of fire, wood is one of the more natural and renewable resources used for heating, compared to oil and gas. In recent years, industrial plants have demanded larger heating-wood materials for more efficient energy production (Kofman, 2006). The process of manufacturing this type of wooden chips is performed with chippers made up of rotating discs or drums (Maier, 1983). The chippers can be stationary or mobile. On one hand, stationary systems are more effective in terms of the throughput capacity, which leads to inexpensive direct-chipping expenses. On the other hand, mobile machines facilitate supply chain management by reducing labour costs associated with transportation (Gold and Seuring, 2011). Furthermore, the dust formation and noise emission of such chippers can be mitigated if the chipper is transported to isolated areas to minimise disturbing possible inhabited regions. For both applications, stationary and mobile, disc or drum chippers are constantly used. The disc chipper produces more homogenous particles with minimal tree fines and oversized chipsand they are more energy efficient than drum chippers (Spinelli et al., 2013) if the wood stock is fed at the correct angle to the disc, according to Johannesson et al. (2012). Drum chippers can provide a higher throughput; therefore, they can increase productivity (Spinelli et al., 2013). When clients request a bigger chip size than what is normally provided, the known boundary conditions characteristics of the machinery used in the forest resources processing changes. This change brings about new challenges because it introduces higher acting loads on the chipping tool and its associated components. To determine the new stress factors and to improve cutting tool durability and efficiency, numerical analysis methods like finite element method are commonly used to analyse physical parameters like stress and strain associated with wood chipping. In this work, a method is presented to determine, analyse and evaluate the main forces acting on the wood chipper tools in a drum chipper. This method will be used in collaboration with experimental measurements and laboratory validation tests. Former investigations in woodworking have focused on measuring wood cutting forces in rotary cutting devices with a cutting depth of up to $1 \mathrm{~mm}$; parameters like wood species, cutting direction, cutting speed, moisture content, geometry influences of the cutting knife have been investigated by several authors (Kivimaa, 1950; Axelsson et al., 1993; Porankiewicz et al., 2011; Cristóvão et al., 2012; Cristóvão, 2013). In recent years, wood-chipping forces with bigger cutting depth is getting more attention. A popular method to measure single-reaction forces during chipping with a drum device is shown in Pfeiffer et al. (2014, 2015) through the use of a series of pendulums like Chardins. The forces are recorded by three-dimensional force sensors, which provide meaningful data about the cutting force associated with a direction while chipping. This type of testing (pendulum) is accomplished by restricting drop height and following velocity 
caused of the usage of gravity. Another approach measures high dynamic forces, as shown in Hellström et al. (2011), using a sensor that is directly mounted on a laboratory-housed disc chipper. Mathematical models to calculate acting chipping forces on bigger cutting depths are not mentioned in aforementioned publications. An approach is suggested on the basis of woodworking with a nonlinear behaviour to calculate the mean cutting force for bigger chips (Maier, 1983). The fact that the cutting force changes during a single cut is already mentioned in Hartler (1963), chipping tests on an anvil and $20 \mathrm{~m} / \mathrm{s}$ of cutting velocity have shown that at the beginning of the chipping process the cutting force arises to a peak and decreases during the whole cutting process. The goal of this study is to measure the strains on the highly dynamic wood-chipping drum in the field operation directly on the blade and to evaluate the acting forces in a validation process by laboratory tests. Another aspect considered in this work is the influence dull knives have on the wood chipping tool load. In addition to a decreasing productivity and a reduction of the feeding efficiency, the fuel consumption also increases. Furthermore, the amount of oversize chips and wood fines is multiplied, which leads to higher expenses due to the need for additional subsequent screening processes (Nati et al., 2010; Facello et al., 2013; Grönlund and Eliasson, 2013; Spinelli et al., 2014; Spinelli and Magagnotti, 2015). Investigations on how to detect worn knives and how to optimise service intervals are shown in Spinelli and Magagnotti (2015). Breakdown of chippers occurs beside of fires (caused of hot engine and exhausting parts) mainly because of drum defects as result of metal objects in the wood (Johansson et al., 2014). Technological advances has improved the durability of chipping drums by using mechanisms that are saving the drum against impurities like unintentional metal parts in the feedstock (Pretzler and Pretzler, 2010). To improve such security measures against metal parts and to increase the durability of chipping tools and its supportive structural parts the knowledge about the angle of the acting force on the chipping blade is important.

\section{Materials and methods}

For the experimental test of this work, a CHIPPO 5010 wood chipper from Komptech $\mathrm{GmbH}$. has been used. An overview of the significant chipper specifications is provided in Table 1.

Strain gauges have been applied to selected areas of a single chipping blade. The supportive knife holder was used to detect the strain on the drum during chipping (Figure 1, left). Signals were transferred, via an external collector ring measuring the rotating drum, to amplify and to store for later analysis (Figure 2). A rela-

\section{Table 1. Summary of chipper specifications.}

\begin{tabular}{lc} 
Power $[\mathrm{kW}]$ & 353 \\
Drum rotation [rad/s] & 46.1 \\
\hline Drum diameter [mm] & 1050 \\
Drum width [mm] & 1023 \\
\hline Cutting blades & 12 \\
\hline
\end{tabular}
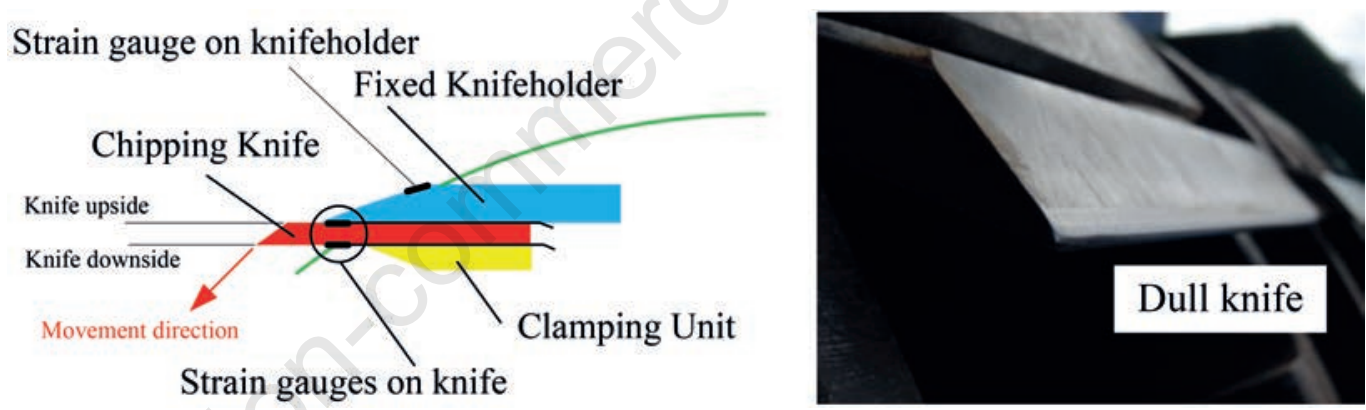

Figure 1. Schematic representation of the positions of the applied strain gauges on the knife, the knife holder (left), and the grinded dull knife (right).

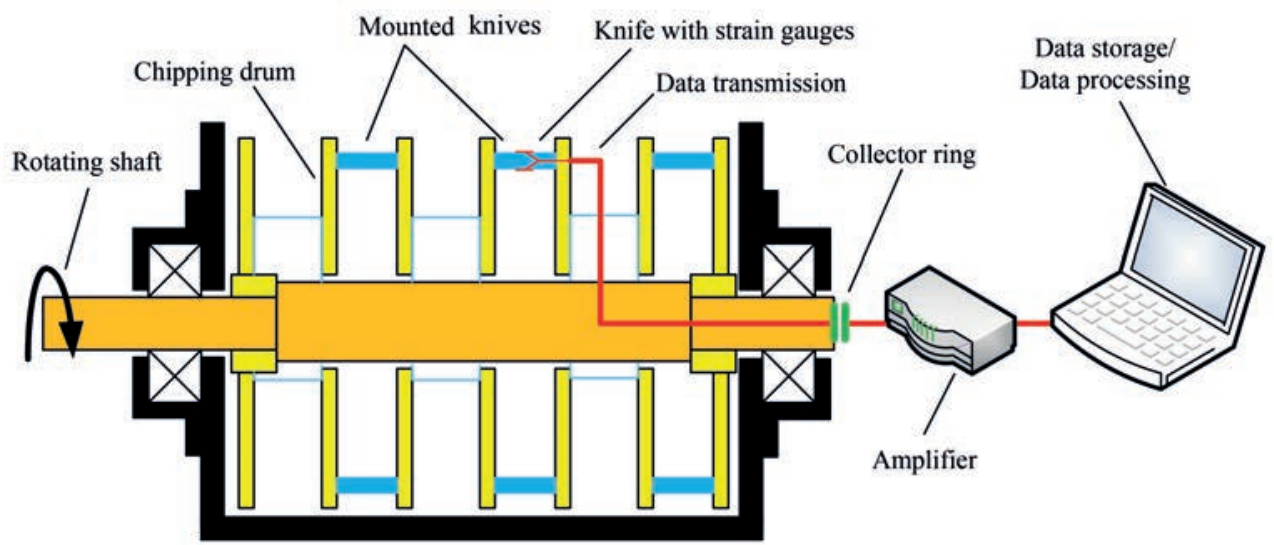

Figure 2. Schematic experimental assembly that will measure the strains on the rotating knife during the high dynamic cutting process. 
tively high sampling rate of $200 \mathrm{kHz}$ was used to ensure reliable results throughout the whole cutting process.

The drum itself was designed as an open drum to ensure that the chips reached the inside of the drum and were not being stored in pre-defined pockets until released to the screen and conveyor unit. The width of the knifes measured $175 \mathrm{~mm}$ on a cutting diameter of $1050 \mathrm{~mm}$ (with a cutting length of $25 \mathrm{~mm}$ ), this correspondents the revolution cylinder of the knife tip. The wood has been horizontally fed to the chipping drum by a track-conveyor, where the distance from the rotational axis to the counter knife was 400 $\mathrm{mm}$ (vertical measure). The rotational speed of the drum at the beginning of the chipping process was $44.5 \mathrm{rad} / \mathrm{s}$ (maximum). To reduce the influence of friction during idle time, screens were removed from the chipper. Each experimental testing setup incorporated up to 10 measured cuts. The average value of all measured strains was utilised for the subsequent comparison with the laboratory test. Fresh wood stems with estimated moisture content between 25 and 35-weight \% were selected for the experiment. The species spruce (Picea), European beech (Fagus sylvatica), hornbeam (Carpinus betulus) in an average diameter of $500 \mathrm{~mm}$ were fed into the chipping drum, the dimension of oak (Quercus) measured $670 \mathrm{~mm}$ in size. The manually adjusted cut length per knife was positioned at 22 and $27 \mathrm{~mm}$, measured radially from the knife tip to the welded drum body. Furthermore, in the setup of the 27-mm service, the knife was modified with a grinder to simulate a dull tool. The resulting knife radius was estimated at $2 \mathrm{~mm}$ (Figure 1, right). To validate the measured strains from the field test and to achieve a conclusion of the acting forces during chipping, a segment of the chipping drum has been manufactured with the same fixture of the chipping knife. To change the angle of the acting load on the blade, a fixture construction for this segment provided a swivel capacity (Figure 3 ). Thus, a swivel angle from a tangential load to the drum, for a load parallel to the knife, was permitted. The designed test-rig has been positioned under a hydraulic cylinder of the MTS System GmbH (Berlin, Germany), which has a maximum load of $250 \mathrm{kN}$. Strain gauges, in the same position as in the field test, applied to the whole drum, have been placed on the segment to supply comparative strains. The material composition has been kept identical to the original chipping drum; therefore, the modified drum was composed of mild steel or heat-treated high-strength steel for highly loaded and abrasive-exposed structural parts. The knife itself consisted of a special steel alloy used for chipping applications.

\section{Results and discussion}

A quite common approach to evaluate loads for the cutting process is based on an average force over cutting time while the knife is in operation (Cristóvão et al., 2012). A close look on the forcetime sequence shows that higher forces occur during a short operation time than the mean cutting force, the course of the chipping force is not constant over time, also mentioned in Hartler (1963). Figure 4 shows the differences between the normalised forces to cutting depth ratio by facilitating the averaging method in Equation 1 (Figure 4, left) and considering the maximum load for each cut using Equation 2 (Figure 4, right). Depending on the method of field-based data analysis, significant differences are achieved (see mean failure factor in Table 2). All load values are normalised to fit the cutting of spruce with $25 \mathrm{~mm}$ cut length using the method of averaging (Figure 4, left):

$$
f_{c, m}=\frac{1}{t_{c u t}} \int_{0}^{t_{c u t}} f(t) \cdot d t
$$

$$
f_{c, \max }=\max f(t)
$$

Table 2 describes the gradient of the linear fit for each wood species, in the form of $y=a x$ (Eq. 3), for the averaging method and the maximum method. Hence, one can observe that the super elevation between the mean and the maximum-value amounts yields a mean failure factor of $1.62( \pm 0.26)$ and $1.81( \pm 0.12)$, respectively. The load peaks do not act over the full cutting time. Even during the short time zones of the highest load peaks, material damage occurs and wears down the structure of the chipping drum over longer times. Every cutting process is analysed. For any wood species, the instantaneous force value for each rotation angle during the cutting period is determined. With the aid of a classification procedure, a load spectrum (collective) is determined for each wood species (Figure 5). For immutable or similar peak values,

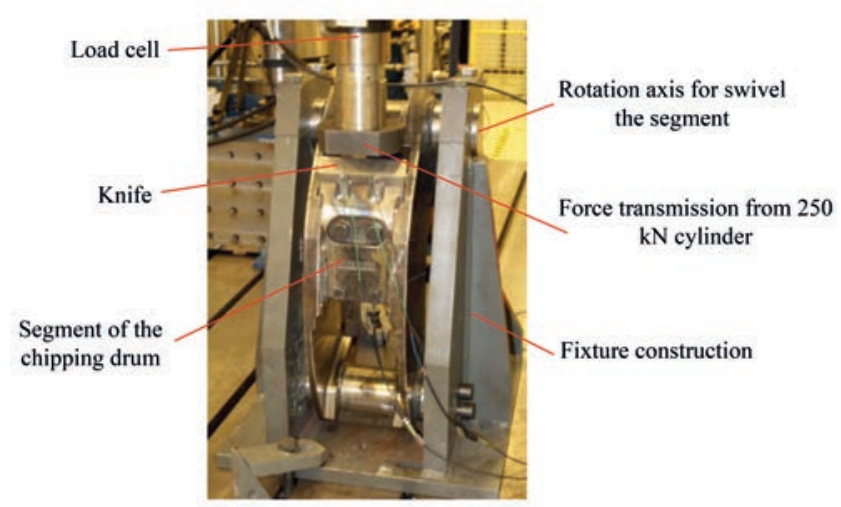

Figure 3. Laboratory segment of the fixture construction and force transmission from the hydraulic cylinder.

\begin{tabular}{|c|c|c|c|c|c|c|}
\hline \multirow{2}{*}{$\begin{array}{l}\text { Wood species } \\
\text { Hornbeam }\end{array}$} & \multicolumn{4}{|c|}{ Linear factor $a$ depending on analysing method } & \multicolumn{2}{|c|}{$\begin{array}{l}\text { Mean failure factor } \\
\text { (max/averaging } \pm \text { STD) }\end{array}$} \\
\hline & 0.0643 & \pm 0.0016 & 0.1164 & \pm 0.0050 & 1.81 & \pm 0.12 \\
\hline European beech & 0.0553 & \pm 0.0049 & 0.0918 & \pm 0.0018 & 1.66 & \pm 0.18 \\
\hline Oak & 0.0563 & \pm 0.0016 & 0.0953 & \pm 0.0098 & 1.69 & \pm 0.22 \\
\hline Spruce & 0.0400 & \pm 0.0046 & 0.0648 & \pm 0.0028 & 1.62 & \pm 0.26 \\
\hline
\end{tabular}

Table 2. Linear parameters and failure-factors between the analysis methods considered. 

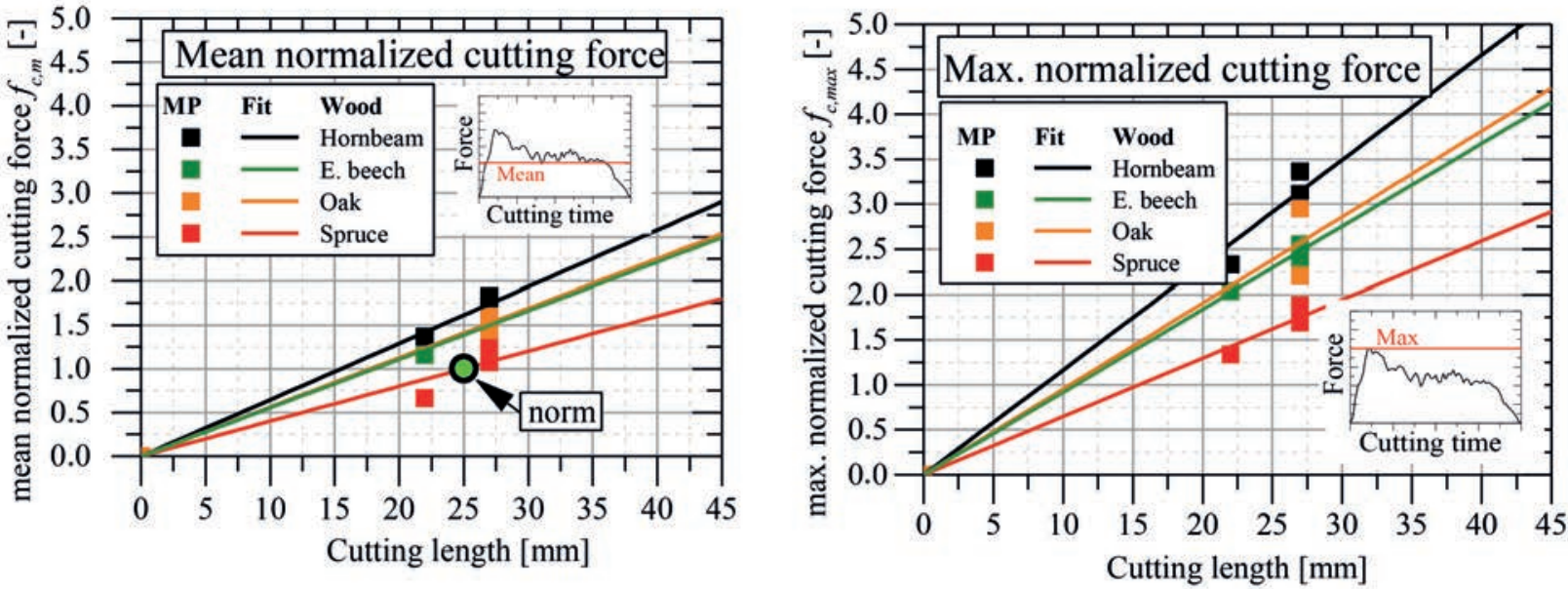

Figure 4. The plotted results of the cutting forces $v$ s cutting service, by taking the mean value over the whole cutting process (left) and the maximum value of the cutting process (right).

$\mathbf{A}$

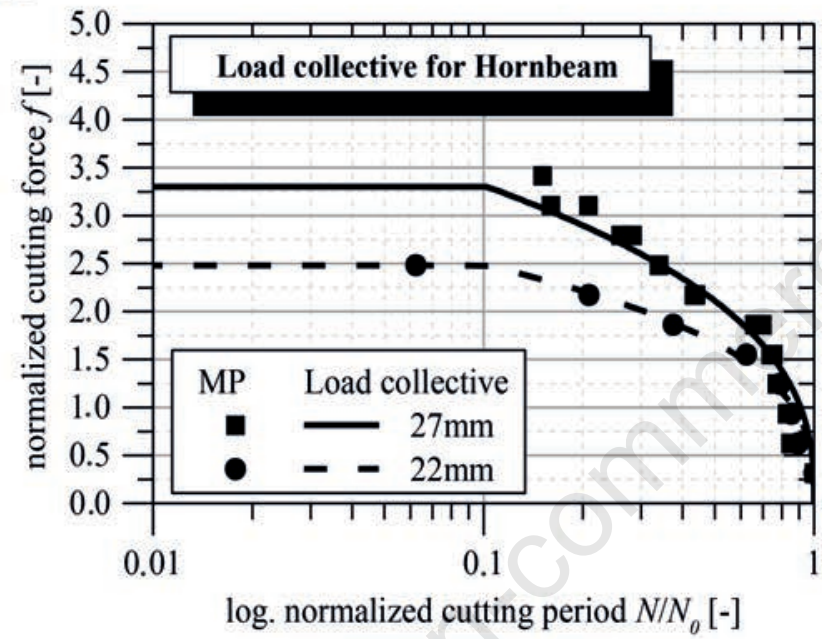

C

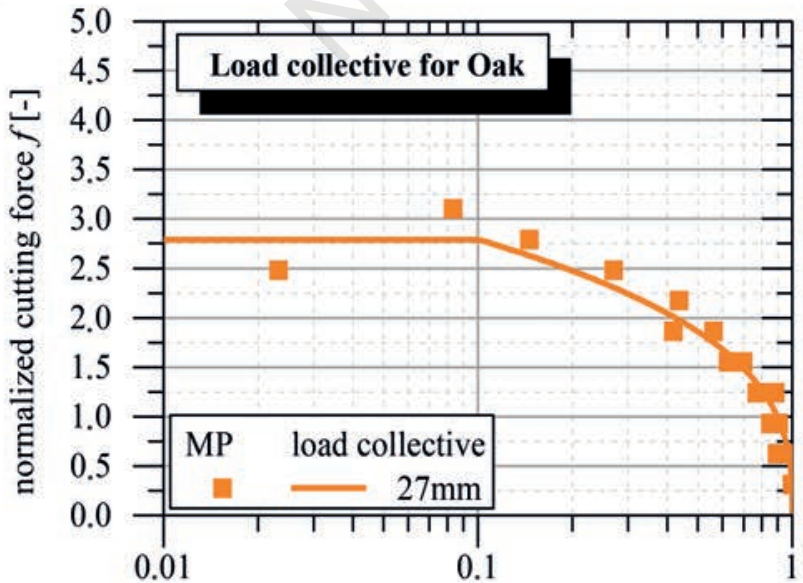

log. normalized cutting period $N / N_{o}[-]$
B

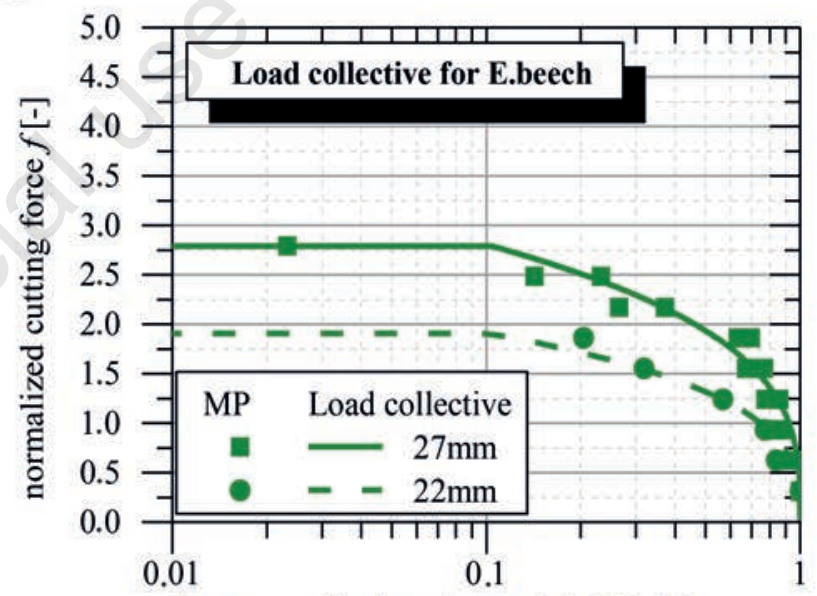

log. normalized cutting period $N / N_{0}[-]$

D

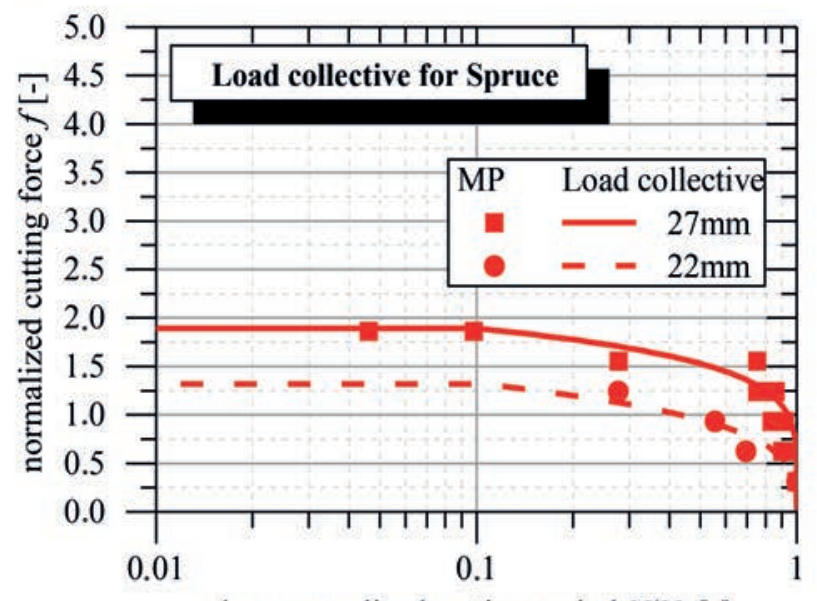

log. normalized cutting period $N / N_{0}[-]$

Figure 5. Proposed normalised load spectra for testing chipping drums by taking load-time dependent, force-based super elevations into account: A) hornbeam; B) European beech; C) oak; D) spruce. 
e.g. attained by cutting processes, a $q$-spectrum is a suggested approach (Radaj, 1990). This kind of spectrum is characterised by a horizontal part, depending of the number of highest loads during the chipping process, and a part that follows Equation 4 for lower forces.

$$
N=N_{0}{ }^{1-}\left(\frac{f}{f_{0}}\right)^{v_{90}-1}
$$

In this formula, $N_{0}$ describes the circumference of the cutting period, $f$ is the normalised acting force, $f_{0}$ is the intend intersection with the vertical axis, and the exponent $v 90^{-1}$ is the curvature form of the load spectrum. By considering each collective, we can easily determine that the kink of the curve in the logarithmic-scale diagram, from the horizontal part of highest load, is approximately a tenth $(10 \%)$ of the whole load spectrum. A summary of the shape factor value $v 90^{-1}$, for $90 \%$ of the cutting period, is listed in Table 3. This information can guide any approach that uses high loads while testing skilled variations of test drums.

Wood is an anisotropic material, leading to different cutting properties, which is dependent of the direction of the wood fibres and the tool movement direction (Kivimaa, 1950). In a drum chipper it depends on the rotational diameter of the drum, the position of the counterknife to the axis of rotation and the sise of the feedstock to describe the angle between the wood fibres and the blade

Table 3. Spectra shape parameters $v_{90} 0^{-1}$ for $90 \%$ of cutting period.

\begin{tabular}{lcccc} 
Cut length & Hornbeam & European beech & Oak & Spruce \\
$22 \mathrm{~mm}$ & $3.06 \pm 0,15$ & $3.22 \pm 0.18$ & - & $5.61 \pm 0.75$ \\
$27 \mathrm{~mm}$ & $2.67 \pm 0.11$ & $3.21 \pm 0.29$ & $2.95 \pm 0.15$ & $3.63 \pm 0.78$ \\
\hline
\end{tabular}

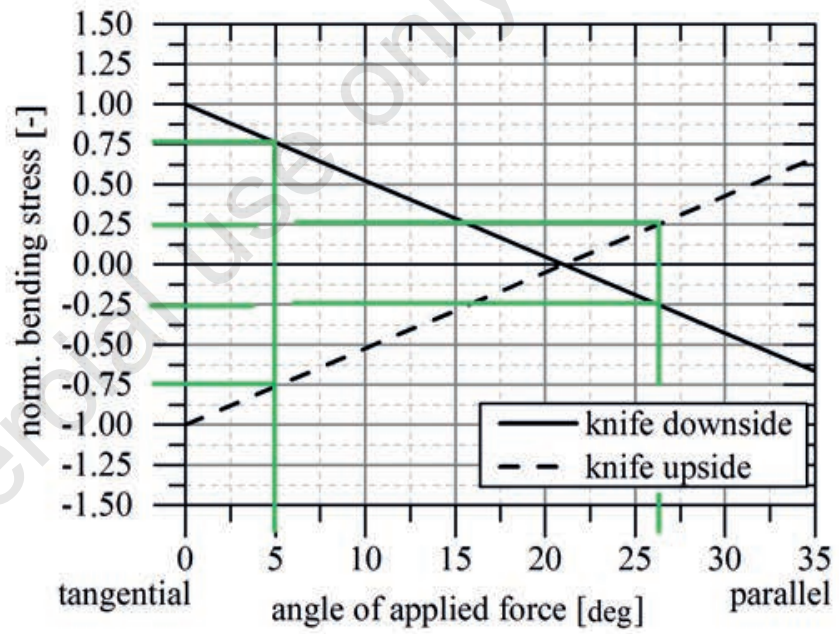

Figure 6. Difference of the stress factors on the cutting knife with sharp and dull tip, and the variation of the stress depending on the swivel angle in the laboratory.

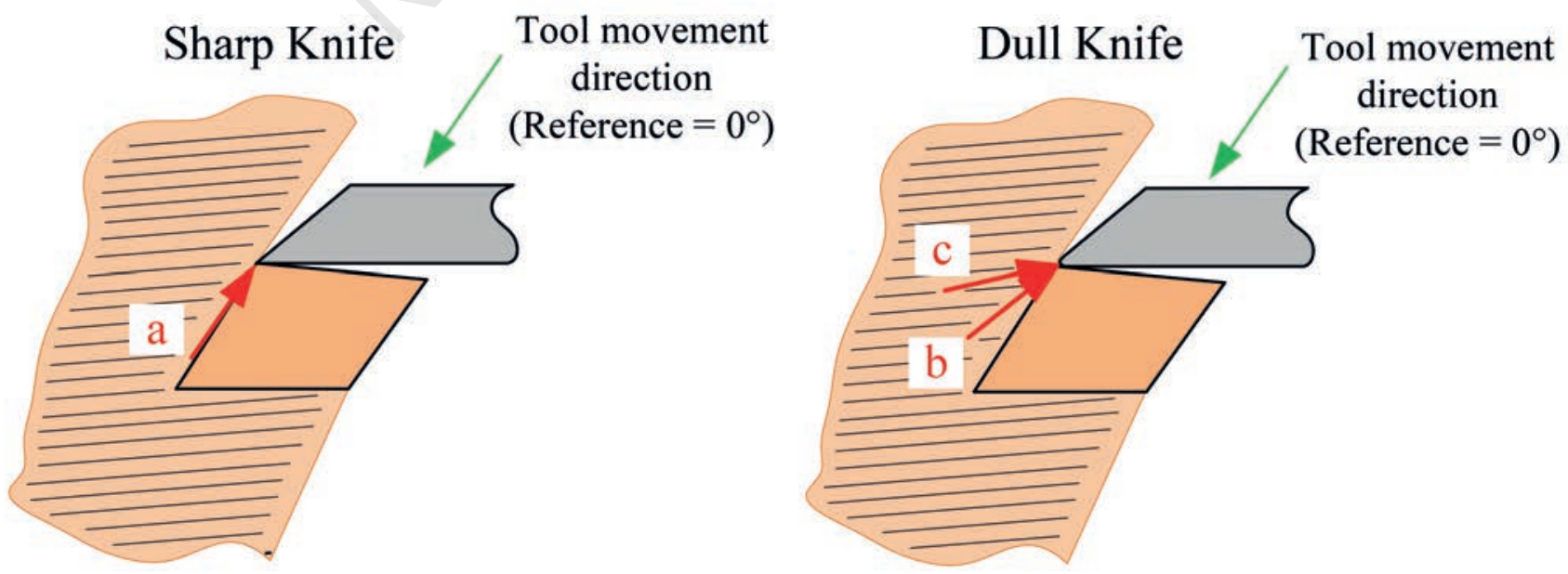

Figure 7. Changing direction of the acting force for a sharp knife in the movement direction (a) a dull knife at the beginning of the cut (b) and at the end of the cut near the counter knife (c). 
movement direction. In the field tests the counterknife is positioned $400 \mathrm{~mm}$ below to the axis of rotation, leading to a decrease of the cutting force at the end of the cut (Figure 6, left) near this area, because the angle between the tool movement direction and the wood fibres is comparably small. Generally, two phenomena are recognisable when comparing the measured and the field data, using a sharply grinded and dull knife. Figure 6 on the left shows the bending stresses on the up- and down-side of the cutting blade during chipping and the time for both configurations. The first phenomenon has the lower stress at the beginning of the cutting process on the worn knife tool. The second is the evident change of stress direction from tension to pressure on the downside and reverse on the up side of the knife, at the end of the cut near the counter knife. A reason for this occurrence may be a changing direction of the acting force applied to the cutting tool during the cut due to the additional friction surface created by the rounded dull knife, which creates a secondary force component on the knife tip. To understand the mechanisms of the test, the laboratory drum segment is swivelled from the position where the acting force is in tangential direction (main knife movement direction), in steps, until the force direction is parallel to the knife. The change of the bending stress with constant load is dependent on the angle of the acting force as illustrated in Figure 6 (right). Under the assumption that the load does not change, as shown in both diagrams, it is possible to determine how the angle of the force direction changes during the cut. At the beginning of the chipping process, with the dull tool, $75 \%$ of the force is reached when compared to the cut with sharp knife. This means that the load direction is five degrees above the tangential position. The change of the bending stresses, from tension to pressure, occurs at about 20 degrees from the tangential. Finally, the $25 \%$ super-elevation, which occurs after the zero crossing, is shown at the end of the chipping process. The super-elevation is achieved with a force direction angle of about 26 degrees from the tangential. This means that the stress on the blade in the reverse position is not new, it is simply the inverse stress due to the load on the opposite side of the knife, i.e., only the angle has changed (Figure 7). This assessment also implies that the feeding efficiency decreases with increasing wear. The change of direction on the acting load reduces the force, which is responsible for the self-feeding of the stem inside the rotating drum. For little cutting depths a similar phenomenon is mentioned in Gottlöber (2014), herein a change of the normal cutting force is described with increasing dullness of woodworking tools, caused of an additional friction surface.

\section{Conclusions}

This paper presents measurements of field tests on an open chipping drum with incorporated strain gauges; the measurements are recorded during the comminution process and laboratory testing is performed to validate the calculated stresses. These field and laboratory tests characterise the forces acting on a wood chipper by processing a variety of wood species. The testing also considers various elevations and periods (time-based) associated with the force distribution measurements. A detailed analysis of the cutting force improves the characterisation of an applied load during a single cut; furthermore, a collection of detailed load-based measurements are used to find the distribution of forces over the cutting period in terms of a normalised cumulative frequency. By using the data from the load spectrum, it is possible to determine elevation-based forces for future physical structural tests on chipping drums. The data analysis has shown that the maximum force can reach 1.6 to 1.8 higher values than the mean force over time. In addition, the investigations show a feasible cause of the decrease in wood-stem self-feeding, by continued increase of wear on cutting blades, such that a change in the angle of the acting force is recognisable. To evaluate the alternative angles in the laboratory, a constant load is used and the change of elevation angle is limited to a deviation from the tangential load direction of 5-26 degrees. To get a detailed analysis of the changing angle and its associated force, field-measurements were also taken using worn knives. The application of a three-dimensional force sensor is scheduled for future investigations.

\section{References}

Axelsson B., Lundberg A.S., Grönlund, A. 1993. Studies of the main cutting force at and near a cutting edge. Holz als Rohund Werkstoff. 51:43-8.

Cristóvão L. 2013. Machining properties of wood- tool wear, cutting forces and tensioning of blades. PhD-thesis. Lulea University of Technology, Skelleftea, Sweden.

Cristóvão L., Broman O., Grönlund A., Ekevad M., Sitoe R. 2012. Main cutting force models for two species of tropical wood. Wood Mater. Sci. Engine. 7:143-9.

Facello A., Cavallo E., Magagnotti N., Paletto G, Spinelli R. 2013. The effect of knife wear on chip quality and processing cost of chestnut and locust fuel wood. Biomass Bioener. 59:468-76.

Gold S., Seuring S. 2011. Supply chain and logistics issues of bioenergy production. J. Clean. Prod. 19:32-42.

Gottlöber C. 2014. Zerspanung von Holz- und Holzwerkstoffen. Grundlagen - Systematik - Modellierung - Prozessgestaltung. FV Leipzig mit Carl Hanser Verlag, Leipzig, Germany.

Grönlund Ö., Eliasson L. 2013. Effect of knife wear on performance and fuel consumption for a small drum chipper. No.:786-2013. Skogforsk Arbetsrapport. Skogforsk, Sweden.

Hartler N. 1963. Some model studies of wood chipping in a laboratory machine. Svensk Papperstidning 66:587-9.

Hellström L.M., Gradin P.A., Gulliksson M. 2011. A laboratory wood chipper for chipping under realistic conditions. Exper. Mechan. 51:1309-16.

Johannesson T., Fogdestam N., Eliasson L. 2012. Effects of chiplength settings on productivity and fuel consumption of a Bruks 605 drum chipper. No.:782-2012. Skogforsk Arbetsrapport. Skogforsk, Sweden.

Johansson F., Grönlund Ö., von Hofsten H., Eliasson L. 2014. Chipper truck breakdowns and their causes. No.:836-2014. Skogforsk Arbetsrapport. Skogforsk, Sweden.

Kivimaa E. 1950. Cutting force in woodworking. PhD-thesis. Finland's Institute of Technology, Helsinki, Finland.

Kofman P.D. 2006. Quality wood chip fuel. COFORD. Dublin (IRL) (Harvesting / Transport and Forest Machinery, no. 6). Available from: http://www.coford.ie/media/coford/content/ publications/projectreports/cofordconnects/finalfuelquality.pdf Accessed: November 2016.

Maier G. 1983. Spanungstechnische Grundlagen der Hackschnitzelerzeugung in Trommelhackern. Holz als Rohund Werkstoff 41:437-9.

Nati C., Spinelli R., Fabbri P. 2010. Wood chips size distribution in relation to blade wear and screen use. Biomass Bioener. 34:583-7.

Pfeiffer R., Collet R., Denaud L.E., Fromentin G. 2014. Analysis 
of chip formation mechanisms and modelling of slabber process. Wood Sci. Technol. 49:41-58.

Pfeiffer R., Lorong P., Ranc N. 2015. Simulation of green wood milling with discrete element method. In: 22nd International Wood Machining Seminar, Bd. 22. International Wood Machining Seminar, Quebec, Canada, pp 57-72.

Porankiewicz B., Axelsson B., Grönlund A., Marklund B. 2011. Main and normal cutting forces by machining wood of Pinus sylvestris. BioResour. 6:3687-713.

Pretzler C., Pretzler R. 2010. Zerkleinerungsmaschine und Werkzeug zum Einsatz in einer Zerkleinerungsmaschine; KOMPTECH GmbH. Appl. No.: EP20100002019; Patent No.: EP 2255882 A1.
Radaj D. 1990. Design and analysis of fatigue resistant welded structures. Cambridge, Abington, UK.

Spinelli R., Cavallo E., Eliasson L., Facello A. 2013. Comparing the efficiency of drum and disc chippers. Silva Fennica 47:1-11.

Spinelli R., Glushkov S., Markov I. 2014. Managing chipper knife wear to increase chip quality and reduce chipping cost. Biomass Bioener. 62:117-22.

Spinelli R., Magagnotti N. 2015. An operator tutoring system for optimal blade maintenance. No.: D2.4. Report. INFRES Innovative and effective technology and logistics for forest residual biomass supply in the EU (311881). Available from: https://cordis.europa.eu/result/rcn/184219_en.html 